Article

\title{
Characterization of Odor-Active Volatiles and Odor Contribution Based on Binary Interaction Effects in Mango and Vodka Cocktail
}

\author{
Yunwei Niu ${ }^{1}$, Pinpin Wang ${ }^{1}$, Qing Xiao ${ }^{2}$, Zuobing Xiao ${ }^{1, *}$, Haifang Mao ${ }^{3}$ and Jun Zhang ${ }^{1}$ \\ 1 School of Perfume and Aroma Technology, Shanghai Institute of Technology, Shanghai 201418, China; \\ nyw@sit.edu.cn (Y.N.); wang_pinpin@163.com (P.W.); zjchem163@163.com (J.Z.) \\ 2 Department of Food Science, Rutgers University, 65 Dudley Road, New Brunswick, NJ 08901, USA; \\ qing.x0619@yahoo.com \\ 3 School of Chemical and Environmental Engineering, Shanghai Institute of Technology, Shanghai 201418, \\ China; mhf@sit.edu.cn \\ * Correspondence: niuge211@sina.com; Tel.: +86-021-6087-3424
}

Received: 3 February 2020; Accepted: 26 February 2020; Published: 28 February 2020

\begin{abstract}
Thirty-six volatile compounds, composed of 18 esters, 10 terpenes, and 8 others, were detected by headspace-solid phase microextraction (HS-SPME) equipped with gas chromatography-mass spectrometry (GC-MS) in mango and vodka cocktail. Moreover, these compounds were detected by olfactometry using aroma intensities. Comparing these compounds revealed that the aroma intensities (AIs) of limonene, 3-carene, myrcene, $\beta$-caryophyllene, and citronellyl propanoate were higher than others (AIs $\geq 4$ ). In this context, limonene was selected as the reference compound on the basis of the strongest component model. The aim of this study was to determine the perceptual interaction between limonene and 3-carene, myrcene, $\beta$-caryophyllene, citronellyl propanoate, respectively, in a binary mixture. In addition, feller's addition model revealed that limonene presented an addition effect when combined with 3 -carene, myrcene, $\beta$-caryophyllene, and citronellyl propanoate. It could be stated that these compounds played an important role in the aroma of mango and vodka cocktail. The results demonstrated that molecular structure and the ratio between compounds affected the synergistic effect, and compounds with similar structure and aroma were more prone to undergo addition and synergy.
\end{abstract}

Keywords: perceptual interaction; synergistic effect; volatile compounds

\section{Introduction}

The aroma is an important driver of the consumers' acceptance. It is affected by the combination of various aromatic ingredients. In recent years, with the advancement of analytical science and technology, the analysis of food aroma has become more and more refined. It is no longer limited to the qualitative and quantitative analysis of aroma compounds. Indeed, the interactions between these compounds have also been studied.

It's known that the contribution of a single aroma compound to the aroma of food is not limited to its concentration in the food material itself but also is affected by its odor threshold in the food matrix [1]. In past studies, it has been shown that the contribution of aroma compounds to the overall aroma depends on the value of its odor activity value (OAV) [2]. However, applying OAV to evaluate the contribution of aroma compounds is based on the hypothesis that there is no interaction between aroma compounds. In fact, there are complex perceptual interactions between aroma compounds in mixtures [3]. Many studies have attempted to investigate the mechanism of perceptual interaction base in binary mixtures or more complex mixtures. The $\sigma-\tau$ notation has been usually 
used to study odor-intensity interaction in a binary mixture [4]. According to Vicente Ferreira [5], there are three levels of possible perceptual interaction: hyper-addition, complete addition, and hypo-addition. The interaction between aroma compounds is affected by the structure and polarity of the molecules. For instance, Georgia Lytra et al. [6] demonstrated the sensory interactions among esters in red wine with Feller's additive model. Ethyl propionate, butyl acetate, and 2-methylpropyl with similar chemical structures significantly decreased blackberry and fresh-fruity odor characteristics. Bénédicte Lorrain et al. [7] found the effects of phenolic compounds on red wine esters at the molecular level. From this study, according to sensory analysis and chemical characteristics, ethyl octanoate with the smallest polarity was greatest influenced by catching addition.

The cocktail is a mixed drink made up of two or more kinds of wine or beverage, juice, and soda. It contains a certain nutritional value and appreciation value [8]. Cocktails are usually based on rum, gin, agave, vodka, whiskey, brandy, and other spirits, followed by juice, egg whites, and so on [9]. Previous studies have mainly focused on volatile compounds about base wines [10] and the influence of accessories on the taste [11].

However, there are very few studies on the analysis of cocktail aromas, especially the perceptual interaction of volatile aroma compounds in a cocktail. The purpose of this study was to determine the odor-active volatiles in a cocktail by GC-MS, gas chromatography-olfactometry (GC-O), and the value of OAV, to study the systematic evaluation of compounds by Feller's additive model and odor activity value coefficient method $(\gamma)$.

\section{Results and Discussion}

\subsection{Olfactometry Analysis of Mango and Vodka Cocktail}

A total of 36 odor-active compounds were perceived by GC-O with the aroma intensity (AI) method (Table 1) in the mango and vodka cocktail. The aroma intensities (AIs) of the odor-active compounds ranged from 0.1 to 4.7. As shown in Table 1, the AI (4.7) value of limonene was the largest in all compounds. Isobornyl acetate showed the lowest AI (0.1).

As shown in Table 1, esters were the greatest class of aroma compounds in the mango and vodka cocktail. This conclusion was consistent with the previous studies of wine. Jorge A et al. [12] found esters were the dominant constituents in mango wine. These are mainly derived from the fatty acid and acetate esters formed enzymatically during fermentation [13] in base wine and produced during the growth process of the added mango juice [14], which contributes to fruity and floral sensory properties to the cocktail $[15,16]$. A total of 18 esters were identified in samples; methyl 2-methyl butanoate, ethyl butanoate, isoamyl butanoate, citronellyl propanoate, hexyl acetate, allyl hexanoate, ethyl octoate, and allyl cyclohexyl propionate all presented AIs $(\geq 3)$. Especially, the AI of citronellyl propanoate was the highest $(=4.1)$ in esters. It contributed to increasing the flavor of the cocktail.

Following the esters were terpenes, and a total of 10 terpenes were detected in mango and vodka cocktail. 3-carene, limonene, myrcene, $\beta$-caryophyllene, $\gamma$-terpinene, $(Z)$ - $\beta$-ocimene, terpinolene presented higher AIs $(\geq 3)$, implying that those compounds were important to the characteristic aroma of mango and vodka cocktail. Among those compounds, 3-carene and limonene were perceived as citrus and sweet aroma. $\beta$-caryophyllene, myrcene, $\gamma$-terpinene, and terpinolene were perceived as woody [17]. (Z)- $\beta$-Ocimene was perceived as having herbal and floral. These compounds provided fruity and woody notes, which were responsible for the fundamental notes of mango and vodka cocktail. The importance of aroma compounds in mango and vodka cocktail was identified by the AIs method, using GC-O and considering the threshold values of aroma compounds [18]. It was not enough to detect the contribution of the aroma compound by AIs alone. Furthermore, OAV was another way to detect the contribution of aroma compounds, which should be combined in mango and vodka cocktail. 
Table 1. Aroma compounds identified by GC-O in mango and vodka cocktail.

\begin{tabular}{|c|c|c|c|c|c|}
\hline \multirow{2}{*}{ NO. } & \multicolumn{2}{|c|}{ RI } & \multirow{2}{*}{ Compound } & \multirow{2}{*}{ Odor Descriptor } & \multirow{2}{*}{ Aroma Intensity } \\
\hline & HP-Wax & DB-5 & & & \\
\hline 1 & 1028 & 776 & Methyl 2-methylbutanoate & sweet, fruity, fatty, green & 3.7 \\
\hline 2 & 1036 & 942 & $(1 R)-(+)$-a-pinene & woody & 0.2 \\
\hline 3 & 1034 & 809 & Ethyl butanoate & fruity & 3.1 \\
\hline 4 & 1077 & 948 & Camphene & woody, herbal & 1.0 \\
\hline 5 & 1111 & 986 & $\beta$-Pinene & dry woody, green & 1.3 \\
\hline 6 & 1123 & 870 & Isoamyl acetate & sweet, fruity & 0.8 \\
\hline 7 & 1156 & 1012 & 3-carene & sweet, fruity & 4.5 \\
\hline 8 & 1153 & 987 & Myrcene & woody, green & 4.2 \\
\hline 9 & 1196 & 1007 & Methyl hexanoate & fruity & 2.0 \\
\hline 10 & 1207 & 1023 & Limonene & citrus, sweet & 4.7 \\
\hline 11 & 1259 & 1064 & $\gamma$-terpinene & woody, citrus & 2.0 \\
\hline 12 & 1266 & 1029 & (Z)- $\beta$-ocimene & warm floral, herb, sweet & 3.6 \\
\hline 13 & 1281 & 1050 & Isoamyl butanoate & fruity, green & 3.8 \\
\hline 14 & 1288 & 1018 & Hexyl acetate & fruity, green, sweet & 3.0 \\
\hline 15 & 1295 & 1100 & Terpinolene & woody, sweet, citrus & 3.4 \\
\hline 16 & 1336 & 1005 & (Z)-3-Hexenyl Acetate & green, sweet, fruity & 1.0 \\
\hline 17 & 1368 & 872 & 1-Hexanol & sweet, green & 1.3 \\
\hline 18 & 1368 & & Allyl hexanoate & sweet, fruity & 3.1 \\
\hline 19 & 1398 & 865 & Leaf alcohol & green & 0.6 \\
\hline 20 & 1453 & 1203 & Ethyl octoate & fruity, wine & 3.8 \\
\hline 21 & 1490 & 964 & Benzaldehyde & sweet, bitter almond & 0.2 \\
\hline 22 & 1542 & 1106 & Linalool & green, floral, sweet & 2.0 \\
\hline 23 & 1593 & 1302 & Menthyl acetate & minty, fruity & 0.2 \\
\hline 24 & 1588 & 1290 & Isobornyl acetate & herb, woody, sweet, minty & 0.1 \\
\hline 25 & 1603 & 1415 & $\beta$-caryophyllene & sweet, woody, spice & 4.0 \\
\hline 26 & 1621 & 1392 & Hexyl hexanoate & herbal, green, fruity & 0.4 \\
\hline 27 & 1660 & 1391 & Ethyl caprate & sweet, fruity & 0.3 \\
\hline 28 & 1658 & 1393 & (Z)-3-Hexenyl hexanoate & fruity, green & 2.8 \\
\hline 29 & 1744 & 1449 & Citronellyl propanoate & floral, green, fruity & 4.1 \\
\hline 30 & 1825 & 1248 & Nerol & sweet, citrus & 0.8 \\
\hline 31 & 1834 & & Allyl cyclohexyl propionate & sweet, fruity & 3.4 \\
\hline 32 & 1853 & 1271 & Geraniol & sweet, floral, fruity & 1.1 \\
\hline 33 & 1851 & 1338 & Benzyl butanoate & fruity & 0.3 \\
\hline 34 & 1944 & 1276 & $\gamma$-Octanoic lactone & fruity, fatty, sweet & 3.2 \\
\hline 35 & 2187 & 1509 & $\gamma$-Decalactone & sweet, fruity, fatty & 3.9 \\
\hline 36 & & 1376 & Neryl acetate & floral & 2.3 \\
\hline
\end{tabular}

Annotation: Identification methods were aroma, RI, and S. Aroma, compounds were identified by comparison to reference standards by GC-O; RI, compounds were identified on HP-Wax and DB-5 by comparison of the reference standard. S, compounds were identified by authentic standards. RI: retention indices; GC-O: gas chromatography-olfactometry.

\subsection{Quantitative Analysis and OAV of Odor-active Compounds}

Thirty-six volatile compounds quantified by GC-MS could be seen in Table 2. The calibration curves for each odor-active compound were established to quantify based on data from six concentration levels. The coefficient of determination of the calibration curve was more than $0.981\left(R^{2}>0.981\right)$, which meant the linearity of each compound was very strong. Although there were many types of esters, the total content of terpenes was the highest. Terpenes played an important role in the mango and vodka cocktail samples. Because the wine contained $20 \%$ mango juice, monoterpene and sesquiterpene were the main aroma components in mangoes [19]. Especially, $(1 R)-(+)-\mathrm{a}-$ pinene $(1364 \mu \mathrm{g} / \mathrm{L}), \beta$-pinene $(752 \mu \mathrm{g} / \mathrm{L}), 3$-carene $(5460 \mu \mathrm{g} / \mathrm{L})$, myrcene $(10900 \mu \mathrm{g} / \mathrm{L})$, limene $(12100 \mu \mathrm{g} / \mathrm{L}), \beta$-caryophyllene $(867 \mu \mathrm{g} / \mathrm{L})$ presented the high concentrations in mango and vodka cocktail. Clara E. Quijano et al. [14] studied that terpene hydrocarbons as the major volatiles of all samples, and $\delta$-3-carene was proved to be the dominant terpene compound. This conclusion was consistent with us.

In addition, the OAVs of methyl 2-methylbutanoate (OAV: 487), 3-carene (OAV: 124), myrcene (OAV: 109), limonene (OAV: 1219), isoamyl butanoate (OAV: 483) were high, which indicated that those compounds contributed a lot to the aroma of mango and vodka cocktail sample. The high concentration of one aroma compound did not mean its OAV was large or conversely [20] because the $\mathrm{OAV}$ was detected by the odor threshold and its concentration. Although $(1 R)-(+)$-a-pinene $(1364 \mu \mathrm{g} / \mathrm{L})$, $\beta$-Pinene $(752 \mu \mathrm{g} / \mathrm{L}), \gamma$-terpinene $(379 \mu \mathrm{g} / \mathrm{L})$, leaf alcohol $(487 \mu \mathrm{g} / \mathrm{L})$, hexyl hexanoate $(461 \mu \mathrm{g} / \mathrm{L})$ showed higher concentrations in mango and vodka cocktail, OAVs of those aroma compounds were less than 1. The main reason was their high odor thresholds. (Z)-3-hexenyl hexanoate $(21.5 \mu \mathrm{g} / \mathrm{L})$ and citronellyl propanoate $(11.9 \mu \mathrm{g} / \mathrm{L})$ presented the low concentrations in the sample. However, these compounds had low thresholds $(1.4 \mu \mathrm{g} / \mathrm{L}$ and $1.8 \mu \mathrm{g} / \mathrm{L})$. What's more, concentrations were much higher than their 
odor thresholds, and their OAV values were greater than 1. OAVs and GC-O should be combined to determine the contribution of aroma compounds to mango and vodka cocktail more accurately. As such, citronellyl propanoate (OAV: 6.6 and AI: 4.1) and $\beta$-caryophyllene (OAV: 14 and AI: 4) had been detected by GC-O because of high AIs, while OAVs were low. This was because synergy occurred between the aroma compounds [6].

Table 2. Standard curves and concentrations of 36 odorants in mango and vodka cocktail by HS/SPME-GC-MS.

\begin{tabular}{|c|c|c|c|c|c|c|}
\hline \multirow{2}{*}{ Compound } & \multicolumn{2}{|c|}{ Standard Curve } & \multirow{2}{*}{$\mathbf{R}^{2}$} & \multirow{2}{*}{ Range $(\mathrm{L}-\mathrm{H})(\mu \mathrm{g} / \mathrm{L})$} & \multicolumn{2}{|c|}{ Wine } \\
\hline & Slope & Intercept & & & $\operatorname{Av}(\mu \mathrm{g} / \mathrm{L})$ & $\operatorname{RSD}^{\mathrm{a}}(\%)$ \\
\hline Methyl 2-methylbutanoate & 0.588 & -0.0277 & 0.998 & $5.62-2249$ & 195 & 3 \\
\hline$(1 R)-(+)$-a-pinene & 0.380 & -0.00710 & 0.998 & $33.1-13,248$ & 1364 & 7 \\
\hline Ethyl butanoate & 0.312 & 0.00840 & 0.981 & $4.70-1880$ & 205 & 2 \\
\hline Camphene & 0.123 & -0.000100 & 0.982 & $0.445-178$ & 56.7 & 8 \\
\hline$\beta$-Pinene & 0.0560 & 0.00370 & 0.988 & $2.97-1188$ & 752 & 5 \\
\hline Isoamyl acetate & 7.36 & 0.00260 & 0.998 & $1.39-554$ & 2.55 & 3 \\
\hline 3-carene & 0.0830 & -0.00180 & 0.993 & $29.4-11,772$ & 5460 & 3 \\
\hline Myrcene & 0.0852 & 0.00280 & 0.990 & $60.4-24,150$ & 10,900 & 7 \\
\hline Methyl hexanoate & 1.67 & 0.00440 & 0.998 & $3.42-1369$ & 29 & 2 \\
\hline Limonene & 0.0951 & 0.108 & 0.999 & $81.6-32,627$ & 12,100 & 6 \\
\hline$\gamma$-terpinene & 0.188 & 0.00160 & 0.995 & $4.71-1885$ & 379 & 2 \\
\hline$(Z)$ - $\beta$-ocimene & 0.184 & -0.000700 & 0.989 & $6.57-2629$ & 556 & 8 \\
\hline Isoamyl butanoate & 2.07 & 0.0558 & 0.996 & $12.1-4821$ & 62.8 & 3 \\
\hline Hexyl acetate & 2.63 & -0.0214 & 0.997 & $9.20-3688$ & 62 & 6 \\
\hline Terpinolene & 0.278 & 0.00280 & 0.982 & $5.38-2151$ & 288 & 7 \\
\hline (Z)-3-Hexenyl Acetate & 1.52 & 0.108 & 0.999 & $29.1-11,640$ & 225 & 5 \\
\hline 1-Hexanol & 0.259 & -0.000500 & 0.999 & $3.92-1570$ & 236 & 3 \\
\hline Allyl hexanoate & 2.56 & -0.0317 & 0.996 & $33.9-13,566$ & 334 & 8 \\
\hline Leaf alcohol & 0.134 & 0.00570 & 0.981 & $4.59-1837$ & 487 & 6 \\
\hline Ethyl octoate & 1.86 & 0.0455 & 0.996 & $10.7-4294$ & 64.6 & 6 \\
\hline Benzaldehyde & 1.62 & -0.00210 & 0.997 & $0.266-106$ & 3.83 & 2 \\
\hline Linalool & 2.95 & 0.137 & 0.997 & $11.6-4640$ & 14.1 & 3 \\
\hline Menthyl acetate & 2.88 & 0.0427 & 0.996 & 3-1199 & 1.23 & 5 \\
\hline Isobornyl acetate & 11.4 & -0.125 & 0.994 & $1.44-576$ & 12.9 & 6 \\
\hline$\beta$-caryophyllene & 0.707 & -0.111 & 0.998 & $32.5-13,011$ & 867 & 2 \\
\hline Hexyl hexanoate & 0.826 & 0.00110 & 0.999 & $24.8-9905$ & 461 & 2 \\
\hline Ethyl caprate & 1.26 & 0.000400 & 0.997 & $0.371-148$ & 4.22 & 4 \\
\hline (Z)-3-Hexenyl hexanoate & 2.02 & 0.0128 & 0.997 & $3.64-1457$ & 21.5 & 8 \\
\hline Citronellyl propanoate & 0.435 & -0.00170 & 0.988 & $4.62-1846$ & 11.9 & 7 \\
\hline Nerol & 2.08 & -0.0208 & 0.993 & $8.57-3426$ & 73.5 & 5 \\
\hline Allyl cyclohexylpropionate & 2.57 & -0.0289 & 0.992 & $26.2-10,475$ & 168 & 7 \\
\hline Geraniol & 2.95 & -0.0554 & 0.987 & $3.83-1533$ & 38.8 & 4 \\
\hline Benzyl butanoate & 3.38 & 0.0859 & 0.995 & $21.8-8703$ & 73.9 & 2 \\
\hline$\gamma$-Octanoic lactone & 0.653 & -0.0102 & 0.981 & $0.401-160$ & 143 & 7 \\
\hline$\gamma$-Decalactone & 1.53 & -0.195 & 0.986 & $5.39-2155$ & 131 & 9 \\
\hline Neryl acetate & 2.55 & 0.336 & 0.993 & $29.1-11,640$ & 44.2 & 6 \\
\hline
\end{tabular}

Annotation: Identification methods were MS, RI, and S. MS, mass spectrum. RI, compounds were identified on HP-Wax and DB- 5 by comparison of the reference standard. S, compounds were identified by authentic standards. ${ }^{a} \mathrm{RSD}$, relative standard deviation.

\subsection{Olfactory Properties of Compounds}

From Tables 1 and 3, the values of AIs and OAVs of limonene, 3-carene, and myrcene were high, which indicated that these three aroma compounds contributed a lot to the aroma of mango and vodka cocktail. Interestingly, citronellyl propanoate and $\beta$-caryophyllene presented the high values of AIs, but lower OAVs. So these five compounds were selected to explore their contributions to the aroma of mango and vodka cocktail. As for the strongest component model [3], limonene was determined as a reference odorant because of its $\mathrm{AI}$ and $\mathrm{OAV}$, and binary interaction effects between key odorant and the reference odorant were assessed to complete the evaluation of odor interaction effects in this study. The P obtained from the experiment was higher than that calculated with Feller's additive model [6] after the four aroma compounds were mixed with the limonene according to the actual concentration ratio in mango and vodka cocktail (Figure 1), respectively. The actual thresholds were less than the theoretical mixing thresholds, and the ratio values ranged from 1.47 to 4.21 . It revealed that synergistic interaction effects occurred to them. In particular, $\beta$-caryophyllene decreased the actual 
threshold significantly, suggesting that $\beta$-caryophyllene could greatly increase the aroma intensity in binary mixtures. A similar perceptual interaction of binary mixtures was observed in previous studies. Margaux Cameleyre et al. [21] focused on the effects of five higher alcohols on esters in red wines. The result showed that the presence of 3-methyl-1-butanol or butanol alone led to a synergy. Jiancai Zhu et al. [22] found that hexanal, 1-octen-3-ol, 3-mercapohexyl acetate, and benzaldehyde decreased the overall threshold value. Although the OAV values of citronellyl propanoate and $\beta$-caryophyllene were 13 and 7 , when they were mixed with limonene, the threshold values were significantly decreased (Figure 1c,d). The synergistic effect resulted in a final aroma intensity value greater than 4 , as shown in Table 1.

Table 3. OAV (odor activity value) of the volatile compound in mango and vodka cocktail.

\begin{tabular}{|c|c|c|c|}
\hline NO & Compound & Odor Threshold ${ }^{\mathrm{a}}(\mu \mathrm{g} / \mathrm{L})$ & OAV \\
\hline 1 & $\begin{array}{c}\text { Methyl } \\
\text { 2-methylbutanoate }\end{array}$ & 0.4 & 487 \\
\hline 2 & $(1 R)-(+)$-a-pinene & 26000 & $<1$ \\
\hline 3 & Ethyl butanoate & 44 & 10 \\
\hline 4 & Camphene & 1860 & $<1$ \\
\hline 5 & $\beta$-Pinene & 1500 & $<1$ \\
\hline 6 & Isoamyl acetate & 30 & $<1$ \\
\hline 7 & 3-carene & 44 & 124 \\
\hline 8 & Myrcene & 100 & 109 \\
\hline 9 & Methyl hexanoate & 87 & $<1$ \\
\hline 10 & Limonene & 10 & 1219 \\
\hline 11 & $\gamma$-terpinene & 1000 & $<1$ \\
\hline 12 & $(Z)-\beta$-ocimene & 34 & 16 \\
\hline 13 & Isoamyl butanoate & 0.13 & 483 \\
\hline 14 & Hexyl acetate & 10 & 6 \\
\hline 15 & Terpinolene & 41 & 7 \\
\hline 16 & (Z)-3-Hexenyl Acetate & 1500 & $<1$ \\
\hline 17 & 1-Hexanol & 5200 & $<1$ \\
\hline 18 & Allyl hexanoate & 40 & 8 \\
\hline 19 & Leaf alcohol & 1000 & $<1$ \\
\hline 20 & Ethyl octoate & 5 & 32 \\
\hline 21 & Benzaldehyde & 5000 & $<1$ \\
\hline 22 & Linalool & 15 & $<1$ \\
\hline 23 & Menthyl acetate & 2000 & $<1$ \\
\hline 24 & Isobornyl acetate & 1800 & $<1$ \\
\hline 25 & $\beta$-caryophyllene & 64 & 14 \\
\hline 26 & Hexyl hexanoate & 6400 & $<1$ \\
\hline 27 & Ethyl caprate & 200 & $<1$ \\
\hline 28 & (Z)-3-Hexenyl hexanoate & 1.4 & 15 \\
\hline 29 & Citronellyl propanoate & 1.8 & 7 \\
\hline 30 & Nerol & 500 & $<1$ \\
\hline 31 & $\begin{array}{l}\text { Allyl cyclohexyl } \\
\text { propionate }\end{array}$ & 2 & 84 \\
\hline 32 & Geraniol & 100 & $<1$ \\
\hline 33 & Benzyl butanoate & 16 & 5 \\
\hline 34 & $\gamma$-Octanoic lactone & 14 & 10 \\
\hline 35 & $\gamma$-Decalactone & 10 & 13 \\
\hline 36 & Neryl acetate & 1.6 & 28 \\
\hline
\end{tabular}

${ }^{\text {a }}$ Odor threshold was determined as in literature [20,23]. 
(a)

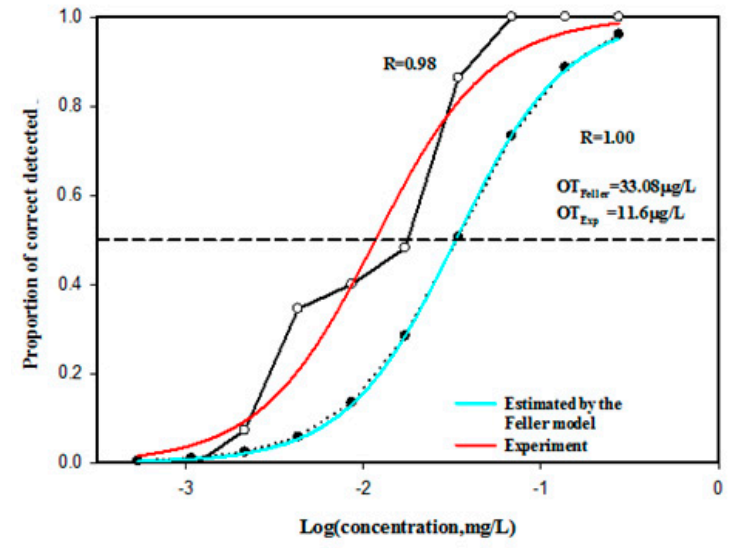

(c)

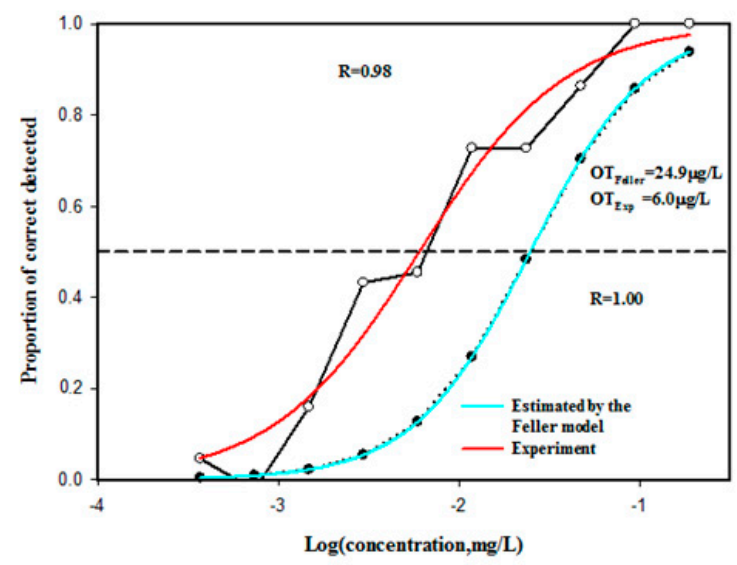

(b)

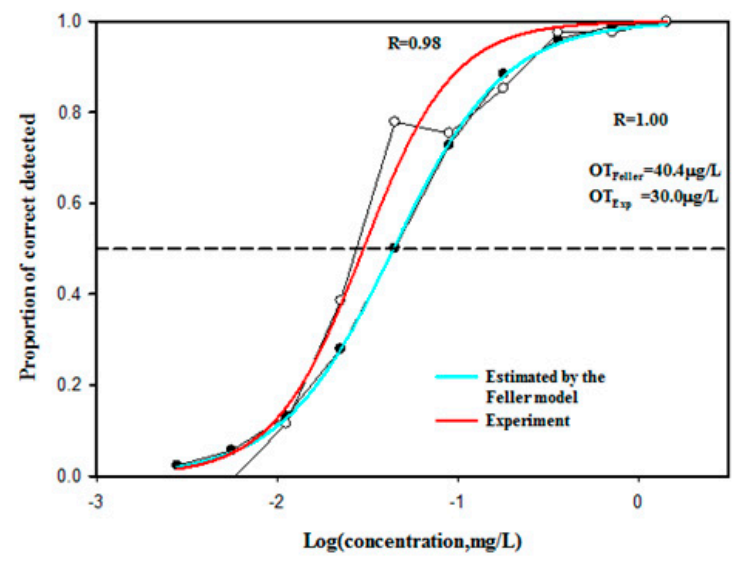

(d)

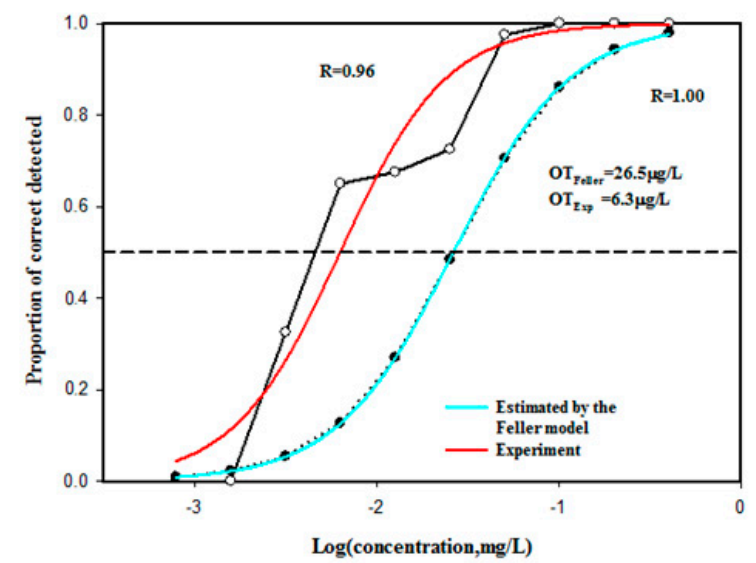

Figure 1. Effect of 3-carene (a), Myrcene (b), Citronellyl propanoate (c), $\beta$-caryophyllene (d) addition on the detection probability of limonene in a binary mixture. OT, olfactory threshold. The curves are drawn according to a sigmoid function.

\subsection{Odor Interaction Effects Evaluated by $\gamma$}

On the basis of the ratio of $O A V_{\text {pure }}$ to $O A V_{\text {mixed }}$ to estimate the perceptual interaction of isointense binary mixtures, thus both type and level of the perceptual interaction of binary mixture could be quantitatively characterized by $\gamma$. The values of $\gamma$ of four key aroma compounds are listed in Table 4 . The $\gamma$ values of 3-carene reduced from 3.60 to 1.06 as $\mathrm{OI}_{\text {mixed }}$ ascended from 2.00 to 5.00, determining that the use of 3-carene was less than it existed alone when 3-carene in the binary mixture reached the same OI as it did alone. So, we concluded 1.06-3.60 times the synergistic interaction effect to 3-carene. But as the intensity increased, the synergistic effect decreased. It indicated that the occurrence of synergy and the degree of action were related to the ratio between the aroma substances. Similar conclusions were reported. Yunwei Niu et al. [24] observed that among the 120 binary mixtures, just 9 mixtures were in the hyper-additivity area; although these compounds were mixed in the same pairs, the effects were different because of the different ratio. Herrmann et al. [25] found that the odor thresholds of $(E)$-2,6-nonadienal and (E)-2-nonenal were significantly decreased by 19.7 and 17.5 times in a binary mixture at the ratio of 10:1. It could be said that the synergistic interaction of (E)-2,6-nonadienal and (E)-2-nonenal was significant, leading to the change of the OAVs. $\gamma$ values of myrcene almost kept 1 , indicating that additive interaction effect happened to myrcene. There was a synergistic interaction when $\mathrm{OI}_{\text {mixed }}$ was 1.95 . The $\gamma$ values of $\beta$-caryophyllene increased from 1.67 to 3.25 , indicating that 1.67 to 3.25 times synergistic interaction effect occurred to $\beta$-caryophyllene. 
Table 4. Example of $\gamma$ values for four key odorants.

\begin{tabular}{ccccc}
\hline \multirow{2}{*}{ OI $^{\mathbf{b}}{ }_{\text {mixture }}$} & \multicolumn{3}{c}{$\gamma^{\mathbf{a}}$ Values } \\
\cline { 2 - 4 } & 3-carene & Myrcene & $\beta$-caryophyllene & Citronellyl Propanoate \\
\hline 2.00 & 3.60 & 1.59 & 1.67 & 1.52 \\
3.00 & 2.43 & 0.92 & 1.87 & 3.84 \\
4.00 & 1.85 & 1.95 & 2.31 & 5.29 \\
5.00 & 1.06 & 1.10 & 3.25 & 8.37 \\
\hline${ }^{a} \gamma:$ odor activity value coefficient. ${ }^{\mathrm{b}}$ OI $_{\text {mixture: }}$ OI (odor intensity) value of the odor mixture.
\end{tabular}

It is interesting that the additive and synergistic effect occurred between limonene and the other four aroma compounds. Limonene, 3-carene, and citronellyl propionate all have the same fruity notes. From the structural point of view, these five compounds all contain unsaturated double bonds. These results were of far-reaching significance for the study of interaction effects between binary mixtures. Similar structured compounds and notes were likely to lead to synergism and addition [26]. In addition, myrcene and $\beta$-caryophyllene have woody notes, and the previous study has reported that woody aroma compounds at sub- and per-threshold concentrations could modify the olfactory perception of supra-threshold fruity notes in wine [27].

\section{Materials and Methods}

\subsection{Materials}

Mango and vodka cocktail ( $330 \mathrm{~mL}, 3.5 \mathrm{vol} \%$ ) used in this study was purchased from Shanghai Bairun Investment Holding Group Co., Ltd. (Shanghai, China) and was chosen for rich juice content (juice $\geq 20 \%$ ), good taste, and high domestic sales in China.

\subsection{Chemicals}

Methyl 2-methylbutanoate, $(1 R)-(+)$-a-pinene, ethyl butanoate, camphene, $\beta$-Pinene, isoamyl acetate, 3-carene, myrcene, methyl hexanoate, dipentene, $\gamma$-terpinene, $(Z)$ - $\beta$-ocimene, isoamyl butanoate, hexylacetate, terpinolene, (Z)-3-hexenyl acetate, 1-hexanol, allyl hexanoate, leaf alcohol, ethyl-caprylate, benzaldehyde, linalool, menthyl acetate, isobornyl acetate, $\beta$-caryophyllene, hexyl hexanoate, ethyl caprate, (Z)-3-Hexenyl hexanoate, citronellyl propanoate, nerol, allyl cyclohexylpropionate, geraniol, benzyl butanoate, $\gamma$-octanoic lactone, $\gamma$-decalactone, neryl acetate, and absolute ethanol were obtained from Shanghai Titan technology Co., Ltd. (Shanghai, China). The 2-octanol, used as internal standards (IS), and a mixture of n-alkane standards (C7-C30) were purchased from Sigma-Aldrich (St. Louis, MO, USA). All of the above chemicals were of GC quality and used without further purification. Ultrapure water was purified from a Milli-Q purification system (Millipore, Bedford, MA, USA).

\subsection{Solid Phase Micro Extraction (SPME) Absorption of Aroma Compounds}

One 50/30 $\mu \mathrm{m}$ carboxyl-divinylbenzene-polydimethylsiloxane (CAR-DVB-PDMS) fiber was selected as the fiber to perform the extraction of cocktail volatiles. The extraction fiber head was $1 \mathrm{~cm}$. Before chemical extraction, a sample volume of $8 \mathrm{~mL}, 2 \mathrm{~g}$ of sodium chloride, and $15 \mu \mathrm{L}$ internal standard solution containing $400 \mathrm{mg} / \mathrm{L}$ of 2-octanol were hermetically sealed in a $15 \mathrm{~mL}$ vial capped with polytetrafluoroethylene-silicone septa. Subsequently, the SPME fiber was exposed to the headspace for $45 \mathrm{~min}$ at $50{ }^{\circ} \mathrm{C}$ in a water bath. The fiber was withdrawn and immediately inserted into the injector of gas chromatography-flame ionization detector-olfactometry (GC-FID-O) and GC-MS for desorption and analysis. The desorption time was $3 \mathrm{~min}$. All the fibers were cleaned between analyses in the GC injector at $250^{\circ} \mathrm{C}$. 


\subsection{Sensory Analyses}

A total of 30 panelists - 15 male and 15 female (age 23-37)—were selected for their ability to determine differences in the flavor of different samples. All panelists were engaged in flavors and fragrances at the School of Perfume and Aroma Technology, Shanghai Institute of Technology.

The above 30 selected panelists accomplished two series of training before the beginning of the experiment. They were required to familiarize themselves with the odor intensity well and strengthen the accuracy of three-alternative forced-choice (3-AFC). The standards of odor intensity were evaluated repeatedly until all panelists could correctly label $100 \%$ of the standards offered. They attended 5 sessions one week, for 2 months.

\subsection{SPME-GC-FID-O Analysis of Mango and Vodka Cocktail}

An Agilent 6890A was equipped with a flame ionization detector (FID) and an ODP-II sniffing port (Mülheim an der Ruhr, Germany). GC effluent was split 1:1 between the FID and sniffing port, respectively. Chromatography was performed in both an HP-INNOWAX fused silica column and a DB-5 fused silica capillary column (both $60 \mathrm{~m} \times 0.25 \mathrm{~mm} \times 0.25 \mu \mathrm{m}$; Agilent Technologies, Santa Clara, CA, USA). Hydrogen was used as a carrier gas at a flow rate of $1 \mathrm{~mL} / \mathrm{min}$. The temperature of the oven was first maintained at $40^{\circ} \mathrm{C}$ for $5 \mathrm{~min}$, and then ramped to $100^{\circ} \mathrm{C}$ at a rate of $3{ }^{\circ} \mathrm{C} / \mathrm{min}$, and ramped to $230^{\circ} \mathrm{C}$ at a rate of $5^{\circ} \mathrm{C} / \mathrm{min}$, and it was maintained for $20 \mathrm{~min}$. The temperatures of the injector and the FID were $250{ }^{\circ} \mathrm{C}$ and $280^{\circ} \mathrm{C}$. Moist air was pumped into sniffing port to quickly remove the odorant eluted from the sniffing port. All panelists had an intimate knowledge of the GC-O technique and trained to recognize odors. The panelists noted the retention time and the odor characteristics of the volatile aroma compounds. Intensity ratings were made using a 1-butanol reference scale procedure. They remarked the intensities of aroma extracts by using a 6-point scale $(0=$ none; $3=$ moderate; $5=$ extreme). Each panelist sniffed each sample twice, and the aroma intensities (AIs) were the average from six panelists.

\subsection{SPME-GC-MS Analysis of Mango and Vodka Cocktail}

Volatile compounds were separated and identified on a 6890 gas chromatograph (GC) coupled to a 5973C mass selective detector (MS) (Agilent Technologies, USA). The volatile compounds were analyzed on an HP-INNOWAX fused silica capillary column and DB-5 fused silica capillary column $\left(60 \mathrm{~m} \times 0.25 \mathrm{~mm} \times 0.25 \mu \mathrm{m}\right.$; Agilent Technologies). The injector temperature was set at $250^{\circ} \mathrm{C}$ for $5 \mathrm{~min}$ desorption from SPME fiber under a splitless mode. Helium was used as a carrier gas with a constant flow rate of $1 \mathrm{~mL} / \mathrm{min}$. Electron impact mass spectrometry was performed, with an electron energy of $70 \mathrm{eV}$ and ion source and interface temperature of $250{ }^{\circ} \mathrm{C}$. The acquisition was performed on scanning mode (mass range $m / z 35-400$ ). The temperate program was the same as for SPME-GC-O. Identification of the aroma compounds was achieved by comparing retention indices (RIs), retention times to those of reference compounds, and mass spectrums in the W8N08.L Database (Hewlett-Packard, Palo Alto, CA, USA). A homologous series of straight-chain alkanes (C7-C30, Sigma-Aldrich, St. Louis, MO, USA) was used to calculate the RIs of unknown compounds.

\subsection{Calibration of Standard Curves}

Six standard solutions of all the volatile compounds at increasing concentrations were prepared by diluting the stock solutions in ethanol, and then $15 \mu \mathrm{L}$ of an internal standard solution containing 2-octanol ( $400 \mathrm{mg} / \mathrm{L})$ was added to establish the calibration curves. These mixture solutions were extracted by HS-SPME under the same conditions as for mango and vodka cocktail. The standard curves, validation range, coefficient of determination $\left(R^{2}\right)$ of the aroma compounds were established and are shown in Table 2. All of the experiments were performed in triplicate. 


\subsection{Odor Threshold and OAV Analysis}

Odor thresholds included determined compounds (3-carene, myrcene, citronellyl propionate, $\beta$-caryophyllene) and reference compound (limonene), 4 mixtures at actual concentration ratio, and 16 isointense mixtures. The odor threshold was measured by an adaptation of the ASTM-E1432 method [28] using 3-AFC in a 3.5\% aqueous ethanol solution.

The probabilities of detection at 10 gradient concentrations (dilution factor was 2) were measured to determine the odor threshold of each target sample in 3 -AFC. The chance effect $(\mathrm{P}=(3 \times \mathrm{p}-$ 1)/2) was used to correct the probability of detection, where $p=$ the experimental probability of detection for each concentration, and $\mathrm{P}=$ the probability of detection corrected by the chance effect. The concentration/response function expressed the relationship between the detection probability and the concentration, which was a psychometric function and fitted a sigmoid curve $\left(\mathrm{P}=1 /\left(1+\mathrm{e}^{\wedge}(-(\mathrm{x}-\right.\right.$ C)/D)) [18]. C was the olfactory threshold of the odorant ( $\log \mathrm{mg} / \mathrm{L}), \mathrm{x}$ was the odorant's concentration (Log $\mathrm{mg} / \mathrm{L}$ ), P was the probability of detection corrected by chance factor. According to definition, when the $\mathrm{P}=0.5, \mathrm{x}=\mathrm{C}$, the concentration was the detection threshold. All of the experiments were replicated in triplicate by panelists. Sigma Plot 12.0 (SYSTAT) software was used for graphic resolution, and ANOVA transforms for nonlinear regression.

The ratio of the concentration of odor to the olfactory threshold (OT) was denoted as OAV.

\subsection{The Measurement of $\gamma$}

Firstly, 3.5\% (vol) ethanol aqueous solution was used to dilute determined aroma compounds and the reference aroma compound, and then was mixed with the different concentrations but the same odor intensity (OI), which formed the isointense mixture. The same odor intensity (OI) was named as $\mathrm{OI}_{\text {target, }}$ and $\mathrm{OI}_{\text {mixture }}$ was the odor intensity of the isointense mixture. The concentrations of determined aroma compounds and the reference aroma compound were adjusted in order to make them reach a series of the same OI values. The perceptual interaction of compounds was measured by $\gamma$ [3] ( $\gamma$ is the ratio value of $O A V_{\text {pure }}$ to $\left.O A V_{\text {mixed }}\right) \cdot \gamma=\frac{O A V_{\text {pure }}}{O A V_{\text {mixed }}}$, where the $\mathrm{OAV}$ of single determined aroma compound was denoted as $\mathrm{OAV}_{\text {pure, }}$ and the OAV of the determined aroma compound in the isointense mixture was denoted as $\mathrm{OAV}_{\text {mixed }}$. $\mathrm{OI}$ and $\mathrm{OI}_{\text {Target }}$ were measured by the sniffing panelists and recorded; $\mathrm{OAV}_{\text {pure }}$ and $\mathrm{OAV}_{\text {mixed }}$ were measured as the ratio of the concentration of aroma compound to its odor threshold. Then, various $O A V_{\text {pure }}$ and $O A V_{\text {mixed }}$ were obtained by adjusting the concentrations of determined aroma compound and reference aroma compound to set a series of isointense binary mixtures.

\subsection{Statistical Analysis}

The analysis of data gained for the concentration of aroma compounds, aroma intensity, odor intensity, and the olfactory threshold was achieved through the statistical software SPSS 17.0. Analysis of variance (ANOVA) was done to determine a significant difference. The statistically significant level was a value of $5 \%(p<0.05)$.

\section{Conclusions}

In this study, the volatile profile of mango and vodka cocktail was evaluated by applying SPME-GC-MS and GC-O. A total of 36 compounds were determined in mango and vodka cocktail. There were 18 esters and 10 terpenes, and the content of terpenes was the highest. Among these compounds, the AIs of limonene, 3-carene, myrcene, $\beta$-caryophyllene, and citronellyl propanoate were higher than others (AIs $\geq 4$ ). Feller's addition model revealed that limonene presented an addition effect combined with 3-carene, myrcene, $\beta$-caryophyllene, and citronellyl propanoate in a binary mixture. According to the $\gamma$ values, the result suggested that molecular structure affected the synergistic effect between compounds, and compounds with similar structure and aroma were more 
prone to undergo addition and synergy. The findings further illustrated that these compounds played an important role in the aroma of mango and vodka cocktail.

Author Contributions: Conceptualization, Y.N., Z.X., and H.M.; Data curation, P.W., Q.X., and J.Z; Formal analysis, P.W., Q.X., and J.Z; Methodology, Y.N., Z.X., and H.M.; Project administration, Y.N. and Z.X.; Supervision, Y.N. and Z.X.; Validation, P.W., Q.X., and J.Z; Writing-original draft, P.W., Q.X., and J.Z; Writing-review and editing, Y.N., Z.X., and H.M. All authors have read and agreed to the published version of the manuscript.

Funding: This work was supported by the National Key Research and Development Program Nanotechnology Specific Project [2016YFA0200304] and National Natural Science Foundation of China [21878187].

Conflicts of Interest: The authors declare no conflict of interest.

\section{References}

1. Czerny, M.; Brueckner, R.; Kirchhoff, E.; Schmitt, R.; Buettner, A. The influence of molecular structure on odor qualities and odor detection thresholds of volatile alkylated phenols. Chem. Senses. 2011, 36, 539-553. [CrossRef] [PubMed]

2. Shu, C.; She, Y.; Xiao, Z.; Xu, L.; Niu, Y.; Zhu, J. Investigations on the Aroma Active Compounds in Fresh and Aged Longjing Tea by SPME/GC-MS/GC-O/OAV. Food Ind. 2016, 37, $279-285$.

3. Wu, C.; Liu, J.; Yan, L.; Chen, H.; Shao, H.; Meng, T. Assessment of odor activity value coefficient and odor contribution based on binary interaction effects in waste disposal plant. Atmos. Environ. 2015, 103, 231-237. [CrossRef]

4. Atanasova, B.; Thomas-Danguin, T.; Langlois, D.; Nicklaus, S.; Etievant, P. Perceptual interactions between fruity and woody notes of wine. Flavour Frag J. 2004, 19, 476-482. [CrossRef]

5. Ferreira, V. Revisiting psychophysical work on the quantitative and qualitative odour properties of simple odour mixtures: a flavour chemistry view. Part 1: intensity and detectability. A review. Flavour Frag J. 2012, 27, 124-140. [CrossRef]

6. Lytra, G.; Tempere, S.; Le Floch, A.; de Revel, G.; Barbe, J. Study of sensory interactions among red wine fruity esters in a model solution. J. Agric. Food Chem. 2013, 61, 8504-8513. [CrossRef]

7. Lorrain, B.; Tempere, S.; Iturmendi, N.; Moine, V.; de Revel, G.; Teissedre, P. Influence of phenolic compounds on the sensorial perception and volatility of red wine esters in model solution: An insight at the molecular level. Food Chem. 2013, 140, 76-82. [CrossRef]

8. Eri, S.; Costa, N.; Trinnaman, L. The Flavor of the Classic Margarita Cocktail. ACS Natl. Meet. Book Abstr. 2006, 179-191.

9. Xin, S.; Zhu, N.; Wang, X.; Zhou, L. Comparative Study of Chinese Liquor and Cocktail Base Wine Based on Electronic Tongue Assessment and Sensory Evaluation. Liquor Making Sci. Tech. 2012, 7, 35-38.

10. Franitza, L.; Granvogl, M.; Schieberle, P. Characterization of the Key Aroma Compounds in Two Commercial Rums by Means of the Sensomics Approach. J. Agric. Food Chem. 2016, 64, 637-645. [CrossRef]

11. Johnson, A.; Hopfer, H.; Heymann, H.; Ebeler, S. Aroma Perception and Chemistry of Bitters in Whiskey Matrices: Modeling the Old-Fashioned. Chemosens Percep. 2017, 1-14. [CrossRef]

12. Pino, J.; Queris, O. Analysis of volatile compounds of mango wine. Food Chem. 2011, 125, 1141-1146. [CrossRef]

13. Sumby, K.; Jiranek, V.; Grbin, P. Ester synthesis and hydrolysis in an aqueous environment, and strain specific changes during malolactic fermentation in wine with Oenococcus oeni. Food Chem. 2013, 141, 1673-1680. [CrossRef] [PubMed]

14. Quijano, C.; Salamanca, G.; Pino, J. Aroma volatile constituents of Colombian varieties of mango (Mangifera indica L.). Flavour Frag J. 2007, 22, 401-406. [CrossRef]

15. Reddy, L.; Kumar, Y.; Reddy, O. Analysis of volatile aroma constituents of wine produced from Indian mango (Mangifera indica L.) by GC-MS. Indian J. Microbiol. 2010, 50, 183-191. [CrossRef] [PubMed]

16. Niu, Y.; Yao, Z.; Xiao, Q.; Xiao, Z.; Ma, N.; Zhu, J. Characterization of the key aroma compounds in different light aroma type Chinese liquors by GC-olfactometry, GC-FPD, quantitative measurements, and aroma recombination. Food Chem. 2017, 233, 204-215. [CrossRef]

17. Cho, S.; Kim, J.; Kim, S.; Park, S.; Kim, J.; Choi, I. A comparative study on the fuel properties of biodiesel from woody essential oil depending on terpene composition. Fuel 2018, 218, 375-384. [CrossRef] 
18. Niu, Y.; Wang, P.; Xiao, Z.; Zhu, J.; Sun, X.; Wang, R. Evaluation of the perceptual interaction among ester aroma compounds in cherry wines by GC-MS, GC-O, odor threshold and sensory analysis: An insight at the molecular level. Food Chem. 2019, 275, 143-153. [CrossRef]

19. Zhou, Y.; Wu, H.; Yao, Q.; Wang, S.; Wei, C.; Ma, X. Changes of Aroma Components in'Keitt'Mango during the Postharvest Period. Agric. Biotechnol. 2014, 3, 14-17.

20. Xiao, Q.; Zhou, X.; Xiao, Z.; Niu, Y. Characterization of the differences in the aroma of cherry wines from different price segments using gas chromatography-mass spectrometry, odor activity values, sensory analysis, and aroma reconstitution. Food Sci. Biotechno. 2017, 26, 331-338. [CrossRef]

21. Cameleyre, M.; Lytra, G.; Tempere, S.; Barbe, J. Olfactory Impact of Higher Alcohols on Red Wine Fruity Ester Aroma Expression in Model Solution. J. Agric. Food Chem. 2015, 63, 9777-9788. [CrossRef] [PubMed]

22. Zhu, J.; Xiao, Z. Characterization of the Major Odor-Active Compounds in Dry Jujube Cultivars by Application of Gas Chromatography-Olfactometry and Odor Activity Value. J. Agric. Food Chem. 2018, 7722-7734. [CrossRef] [PubMed]

23. Gemert, L. Compilations of Odour Threshold Values in Air, Water and Other Media; Boelens Aroma Chemical Information Service: Huizen, The Netherlands, 2003.

24. Niu, Y.; Yao, Z.; Xiao, Z.; Zhu, G.; Zhu, J.; Chen, J. Sensory evaluation of the synergism among ester odorants in light aroma-type liquor by odor threshold, aroma intensity and flash GC electronic nose. Food Res. Int. 2018, 113, 102-114. [CrossRef] [PubMed]

25. Herrmann, M.; Klotzbücher, B.; Wurzbache, M.; Hanke, S.; Kattein, U.; Back, W.; Becker, T.; Krottenthaler, M. A new validation of relevant substances for the evaluation of beer aging depending on the employed boiling system. J. Inst. Brew. 2010, 116, 41-48. [CrossRef]

26. Zhu, J.; Chen, F.; Wang, L.; Niu, Y.; Xiao, Z. Evaluation of the synergism among volatile compounds in Oolong tea infusion by odour threshold with sensory analysis and E-nose. Food Chem. 2017, 221, 1484-1490. [CrossRef]

27. Atanasova, B.; Thomas-Danguin, T.; Chabanet, C.; Langlois, D.; Nicklaus, S.; Etievant, P. Perceptual interactions in odour mixtures: odour quality in binary mixtures of woody and fruity wine odorants. Chem Senses 2005, 30, 209-217. [CrossRef]

28. Cometto-Muñiz, J.; Abraham, M. Human olfactory detection of homologous n-alcohols measured via concentration-response functions. Pharmacol. Biochem. Behav. 2008, 89, 279-291.

Sample Availability: Samples of the compounds are available from the authors.

(C) 2020 by the authors. Licensee MDPI, Basel, Switzerland. This article is an open access article distributed under the terms and conditions of the Creative Commons Attribution (CC BY) license (http://creativecommons.org/licenses/by/4.0/). 